\title{
Tracking the progress of climate change adaptation: an Australian case study
}

Jean P. Palutikof $1,2,4$

Sarah L. Boulter ${ }^{1,2}$ Email: s.boulter@griffith.edu.au

Frank Stadler ${ }^{1,3}$ Email: f.stadler@griffith.edu.au

Ana C. Perez Vidaurre ${ }^{1}$ Email: anacecilia88@hotmail.com

${ }^{1}$ National Climate Change Adaptation Research Facility, Griffith University, Gold Coast, Queensland 4222, Australia

${ }^{2}$ Cities Research Institute, Griffith University, Gold Coast, Queensland 4222, Australia

${ }^{3}$ Department of Business Strategy and Innovation, Griffith University, Gold Coast, Queensland 4222, Australia

${ }^{4}$ Corresponding author:

Email: j.palutikof@griffith.edu.au

Phone: +61 (0)75552 7734

ORCID No.: 0000-0002-5248-6925

\section{Funding source:}

This research did not receive any specific grant from funding agencies in the public, commercial, or not-for-profit sectors.

\begin{abstract}
The last decade has seen strong global growth in the number of climate change adaptation projects. To understand whether adaptation is progressing and is successful, some form of longitudinal tracking is required. The six adaptation conferences organised by the National Climate Change Adaptation Research Facility between 2010 and 2018 provide a unique and novel opportunity to track adaptation progress in Australia. Each conference was accompanied by a call for abstracts for oral or poster presentation. The submitted abstracts form the basis of the analysis in this paper. We show that, over time, the balance of attendees shifted away from researchers and towards government employees, and the proportion of attendees submitting abstracts declined. The proportion of abstracts submitted by government employees and consultants has increased at more recent conferences. When abstract content is analysed, the results show that, over time, there has been a change in the focus of abstracts with respect to the sector, type and stage of adaptation. These trends indicate maturation of adaptation in Australia, but also suggest that lack of finance for research and action is having an impact. There is evidence that adaptation in Australia is moving from being largely planning based and towards implementation. This is encouraging, given that studies throughout the world have remarked on the barriers that exist in moving from planning to action.
\end{abstract}

Keywords: Climate change adaptation; Tracking; Planning; Implementation; Financing; Conference abstracts 


\section{Vitae}

Jean Palutikof is Professor and Director of the National Climate Change Adaptation Research Facility, Griffith University, Australia, a role she assumed in October 2008. Previously, she managed production of the Intergovernmental Panel on Climate Change Fourth Assessment Report for Working Group II (Impacts, Adaptation and Vulnerability), while based at the UK Met Office. From 1979 to 2004 she worked at the University of East Anglia, UK, becoming a Professor in the School of Environmental Sciences, and Director of the Climatic Research Unit. Before that, she was a Lecturer at the Department of Geography, University of Nairobi, Kenya, 1974-1979.

Sarah Boulter is Senior Research Fellow at NCCARF where her work has focused on extreme events and the lessons for adaptation, biodiversity, assessment of forest vulnerability and policy guidance. Her most recent projects include developing the Biodiversity and Ecosystem Climate Adaptation Plan for the Queensland Government, and an Adaptation Handbook for the Australian Department of Defence. Before joining NCCARF she held roles at Griffith University researching the impacts of climate change on plant reproduction and biodiversity and with the Queensland Government in science communication and policy related to vegetation management and impact assessment in Moreton Bay.

Frank Stadler was research coordinator at the Australian National Climate Change Adaptation Research Facility (NCCARF) from 2008 to 2013. Thereafter, he completed a doctoral degree investigating the supply chain management for maggot debridement therapy in compromised healthcare settings. He is now Research Fellow with the School of Medicine, and Adjunct Research Fellow at the Department of Business Strategy and Innovation where he continues to work on climate change adaptation.

Ana Perez is an Environmental Engineer with a proven track record in design, coordination and delivery of environmental initiatives. In her role of Environmental Coordinator at the Americas Fund of Peru she managed local and regional conservation programs involving a diverse set of stakeholders. After finalising her Master's Degree in Climate Change Adaptation she worked for over three years in Australia's National Climate Change Adaptation Research Facility, where she contributed to the development of a coastal risk management tool, CoastAdapt. She currently works at the Great Barrier Reef Foundation as a Program Manager of the Reef Trust Partnership. 


\section{Introduction}

The Paris Agreement came into being in 2016 at the $21^{\text {st }}$ Conference of the Parties of the United Nations Framework Convention on Climate Change (UNFCCC) (Kinley 2017). Although most widely known for its goal of limiting global surface temperature increase to 'well below' $2^{\circ} \mathrm{C}$ above preindustrial levels (Leemans and Vellinga 2017), it is also notable for the prominence it gave to the need for adaptation to address the impacts of climate change (Morgan et al. 2019). The Agreement, together with earlier instruments such as the Green Climate Fund (Bowman and Minas 2019), have meant that the last decade has been marked by strong global growth in the number of adaptation projects (Biagini et al. 2014; Donner et al. 2016).

Awareness of the need for adaptation and availability of financing are necessary but insufficient conditions for adaptation to take place. In addition, there needs to be motivation to undertake the full adaptation process, from identifying potential impacts and risks, through to evaluating adaptation options, planning for action, undertaking action and, finally, evaluating the outcomes. This is often characterised as a risk management process (Tonmoy et al. 2019).

To understand whether adaptation is progressing and is effective, it is necessary to assess, measure or track adaptation 'success'. There are many barriers to adaptation which arise at different stages of the process (Barnett et al. 2015), and which hinder progress. Adaptation tracking supports understanding of what these barriers are, how they impact on the adaptation process, and how they can be overcome (Ford and King 2015). Despite its importance, there have been few attempts to develop systematic approaches to tracking adaptation. Ford and Berrang-Ford (2016) identify four approaches: with an emphasis on progress, process, diversity and quality.

Many studies of adaptation tracking are based on analysis of published papers and reports. Some focus on grey literature analyses, for example of National Adaptation Programmes of Action (NAPAs) and National Adaptation Plans (NAPs) submitted to the UNFCCC (Morgan et al. 2019), others review publications in the academic literature (Pearce et al. 2018), and some explore both (e.g., Ford et al. 2013). Analyses have been carried out at the global scale, comparing progress in adaptation between countries (Ford and Berrang-Ford 2016; Lesnikowski et al. 2015; Lesnikowski et al. 2016) and for individual countries, for example water management in the Netherlands (Kamperman and Biesbroeck 2017), public health in Canada (Austin et al. 2015) and among local governments in Australia (Bradley et al. 2015; Moloney and McClaren 2018). Ray and Grannis (2015) analysed progress in the implementation of State Climate Change Adaptation Plans in the U.S.

Alternative approaches are based on the development of indicators of progress. Indicators may be direct, for example a count of the number of adaptation projects (GIZ 2014), or indirect, for example measuring vulnerability and using a reduction as a proxy signal for successful adaptation (e.g., Suk et al. 2014). Combinations have been developed, for example a continually-updated global adaptation index based on a combination of a country's current vulnerability to climate disruptions with its readiness to leverage private and public sector investment for adaptive actions (Chen et al. 2015). GIZ (2014) compared ten aggregate indicator-based tracking systems according to their context, processes and content.

The identification and tracking of indicators is not straightforward (Ford et al. 2013). Street et al. (2017) identified widely-recognised issues when they stated with respect to the 2017 UK Climate Change Risk Assessment that "many of the available indicators to measure adaptation progress are data-driven rather than use-driven; and there is no routine collection of data and other evidence to assess whether policies are successful in achieving their objectives". 
In terms of sectors, studies do not point to globally homogeneous patterns. For example, in a search of the global peer-reviewed literature (extracted from Web of Knowledge), Ford et al. (2011) found that 'adaptations are most commonly documented in the transportation, infrastructure and utilities sectors' whereas Pearce et al. (2018) in a multisectoral study of the Australian peer-reviewed literature noted that $30 \%$ of articles studied focused on agriculture.

In this paper, we take a different approach to tracking adaptation. By analysing abstracts submitted to a series of adaptation-related conferences over a period of close to a decade, we seek to understand the characteristics of the adaptation community, how adaptation evolved over time and what the drivers of that evolution might be.

In terms of the four approaches to adaptation tracking identified by Ford and Berrang-Ford (2016), this study addresses progress (from articulating goals to planning to implementation) and diversity (of adaptation policies, and of impacts and sectors addressed). The brevity of the source data for the investigation does not allow exploration of adaptation quality. The fourth approach, process, looks at procedural aspects of adaptation such as inclusion of key stakeholders, consideration of uncertainties, and project monitoring and evaluation. We touch on this only tangentially.

\section{Background}

In 2008 the National Climate Change Adaptation Research Facility (NCCARF) was set up by the Australian Government to "lead the research community in a national interdisciplinary effort to generate the information needed by decision-makers in government and in vulnerable sectors and communities to manage the risks of climate change impacts" (NCCARF 2014). With a budget of around 50 million AUD over five years, it achieved its goals through a suite of activities including identification of knowledge gaps, research programs to address the identified knowledge gaps, and network and capacity building (Pearce et al. 2018; Ling and Hobday 2019). Subsequently, NCCARF received a second round of funding for 2014-17 to provide capacity development and support for adaptation, with a focus on the Australian coast (Pearce et al. 2018).

As part of its activities, and in order to grow knowledge exchange and capacity to adapt, NCCARF instituted a conference series focused specifically on adaptation. Experience suggested that climate change impacts and adaptation were often topics covered in climate change conferences, but that the main focus was generally on the physical science, with impacts and adaptation having a relatively minor role. The goal of the NCCARF conference series was to put adaptation centre stage.

Table 1 provides background information on each conference. Conferences occurred at approximately two-yearly intervals. As part of the process of building partnerships in the adaptation community in Australia, NCCARF sought a co-organiser for each conference. For the first five, this was the Commonwealth Scientific and Industrial Research Organisation (CSIRO), and for the 2018 conference it was Engineers Australia, the professional society for engineers in Australia. The title of each conference provided a theme (shown in Table 1), but these were sufficiently general that anyone working in any capacity in climate change adaptation would consider the conference an appropriate venue at which to usefully network and present their work. Fees were in the range 9501100 AUD for full registration and 500-575 AUD for students over the six conferences. These are typical amounts for large conferences in Australia, and the variation over time is insufficient to have any impact on attendances. Researchers receiving NCCARF funds were not required to attend conferences, although many took the opportunity to present their projects. 
Table 1 Information on the NCCARF Climate Adaptation conference series 2010 - 2018

\begin{tabular}{|c|c|c|c|c|c|c|}
\hline & 2010 & 2012 & 2013 & 2014 & 2016 & 2018 \\
\hline Location & $\begin{array}{l}\text { Gold Coast, } \\
\text { Queensland }\end{array}$ & $\begin{array}{l}\text { Melbourne, } \\
\text { Victoria }\end{array}$ & $\begin{array}{l}\text { Sydney, New } \\
\text { South Wales }\end{array}$ & $\begin{array}{l}\text { Gold Coast, } \\
\text { Queensland }\end{array}$ & $\begin{array}{l}\text { Adelaide, } \\
\text { South } \\
\text { Australia }\end{array}$ & $\begin{array}{l}\text { Melbourne, } \\
\text { Victoria }\end{array}$ \\
\hline $\begin{array}{l}\text { Title and } \\
\text { theme: }\end{array}$ & $\begin{array}{l}\text { Climate } \\
\text { Adaptation } \\
\text { Futures: } \\
\text { preparing } \\
\text { for the } \\
\text { unavoidable } \\
\text { impacts of } \\
\text { climate } \\
\text { change }\end{array}$ & $\begin{array}{l}\text { Climate } \\
\text { Adaptation } \\
\text { in Action } \\
\text { 2012: } \\
\text { sharing } \\
\text { knowledge } \\
\text { to adapt }\end{array}$ & $\begin{array}{l}\text { Climate } \\
\text { Adaptation } \\
\text { 2013: } \\
\text { knowledge + } \\
\text { partnerships }\end{array}$ & $\begin{array}{l}\text { Climate } \\
\text { Adaptation } \\
\text { 2014: future } \\
\text { challenges }\end{array}$ & $\begin{array}{l}\text { Climate } \\
\text { Adaptation } \\
\text { 2016: } \\
\text { change, } \\
\text { challenge, } \\
\text { opportunity }\end{array}$ & $\begin{array}{l}\text { Climate } \\
\text { Adaptation } \\
\text { 2018: learn, } \\
\text { collaborate, } \\
\text { act }\end{array}$ \\
\hline $\begin{array}{l}\text { Registration } \\
\text { fee (AUD; EB = } \\
\text { early bird; } \\
\text { Stud = } \\
\text { student) }\end{array}$ & $\begin{array}{l}E B=\$ 850 \\
\text { Full }=\$ 1100 \\
\text { Stud }=\$ 500\end{array}$ & $\begin{array}{l}E B=\$ 750 \\
\text { Full }=\$ 950 \\
\text { Stud }=\$ 500\end{array}$ & $\begin{array}{l}E B=\$ 750 \\
\text { Full }=\$ 950 \\
\text { Stud }=\$ 500\end{array}$ & $\begin{array}{l}E B=\$ 800 \\
\text { Full }=\$ 1000 \\
\text { Stud }=\$ 550\end{array}$ & $\begin{array}{l}E B=\$ 850 \\
\text { Full }=\$ 1000 \\
\text { Stud }=\$ 550\end{array}$ & $\begin{array}{l}\text { EB }=\$ 900 \\
\text { Full }=\$ 1050 \\
\text { Stud }=\$ 575\end{array}$ \\
\hline $\begin{array}{l}\text { Partners } \\
\text { organisation } \\
\text { with NCCARF }\end{array}$ & CSIRO & CSIRO & CSIRO & CSIRO & CSIRO & $\begin{array}{l}\text { Engineers } \\
\text { Australia }\end{array}$ \\
\hline $\begin{array}{l}\text { Number of } \\
\text { attendees } \\
\text { (Total }=3568 \text { ) }\end{array}$ & 1022 & 618 & 575 & 451 & 495 & 407 \\
\hline $\begin{array}{l}\text { Number of } \\
\text { submitted } \\
\text { abstracts } \\
\text { relevant to } \\
\text { Australia (see } \\
\text { text for } \\
\text { explanation) } \\
\text { (Total = 1904) }\end{array}$ & 409 & 469 & 327 & 312 & 245 & 142 \\
\hline $\begin{array}{l}\text { Abstracts as a } \\
\text { percent of } \\
\text { attendees (\%) }\end{array}$ & 40.0 & 75.9 & 56.9 & 69.2 & 49.5 & 34.9 \\
\hline $\begin{array}{l}\text { Number of } \\
\text { presented } \\
\text { abstracts } \\
\text { (Total }=1877 \text { ) }\end{array}$ & 399 & 469 & 322 & 299 & 245 & 142 \\
\hline
\end{tabular}

The first conference, held in 2010, had the role of bringing NCCARF to the attention of the adaptation community both nationally and internationally. As such, it was organised as an international event, with around 30 invited participants from the overseas adaptation community, contributing as plenary speakers, discussion panel organisers, or in a related capacity. All subsequent conferences were organised as national events, with just 2-3 speakers invited from overseas. All conferences were preceded by a call for abstracts for oral or poster presentations. It is the abstracts submitted in response to this call which form the basis of the analysis in this paper.

The abstracts submitted over the six conferences between 2010 and 2018 provide an opportunity to explore the progress of adaptation in Australia. We can expect that adaptation practitioners will 
submit abstracts based on their work experience, and that researchers will submit abstracts based on their projects - what they plan to do, or what the results are. Abstract content is thus a measure of what is viewed as important by those responsible for funding adaptation action or research. The submitted abstracts are therefore a reflection, however imperfect, of adaptation policy and action in Australia. By tracking how abstracts change over the course of the six conferences, we can draw conclusions about the evolution of adaptation in Australia for close to a decade.

\section{Management of conference abstracts}

For each conference, a list of adaptation-related topics was advertised and people submitting an abstract were required to identify the topic they wished it to be considered for. Generally speaking, the themes changed little if at all between conferences. They were either sectoral (water resources, agriculture, human health etc.) or related to systemic or theoretical issues (barriers and limits to adaptation, adaptation and development, adaptation monitoring and evaluation etc.) An 'Other' category was always included in the call. Abstracts were reviewed by a panel drawn from NCCARF employees and external experts. Few abstracts were rejected (see Table 1) and rejection generally only occurred if an abstract was completely out-of-scope, for example related to the physics of general circulation models. Finally, abstracts were organised into topics which became the titles of parallel sessions at the conferences. Table 2 shows the occurrence of these titles throughout the conference series. In the table, we have simplified session titles: for example, Water management may refer to, for example, Water sector adaptation: innovations (2010) or Water management and governance under increased climate variability and change (2018). 
Table 2: Parallel session topics at the NCCARF conferences

\begin{tabular}{|c|c|c|c|c|c|c|}
\hline & 2010 & 2012 & 2013 & 2014 & 2016 & 2018 \\
\hline Agriculture & $\checkmark$ & $\checkmark$ & $x$ & $\checkmark$ & $\checkmark$ & $\checkmark$ \\
\hline Cities, built environment, urban devel. & $\checkmark$ & $\checkmark$ & $\checkmark$ & $\checkmark$ & $\checkmark$ & $\checkmark$ \\
\hline Coasts & $\checkmark$ & $\checkmark$ & $\checkmark$ & $\checkmark$ & $\checkmark$ & $\checkmark$ \\
\hline Cognitive \& behavioural change & $\checkmark$ & $\checkmark$ & $\checkmark$ & $x$ & $x$ & $\checkmark$ \\
\hline Climate science \& scenarios & $\checkmark$ & $\checkmark$ & $\checkmark$ & $x$ & $\checkmark$ & $x$ \\
\hline Communication & $\checkmark$ & $\checkmark$ & $\checkmark$ & $\checkmark$ & $\checkmark$ & $\checkmark$ \\
\hline Communities & $\checkmark$ & $x$ & $\checkmark$ & $\checkmark$ & $\checkmark$ & $\checkmark$ \\
\hline Disaster management & $\checkmark$ & $x$ & $\checkmark$ & $\checkmark$ & $\checkmark$ & $\checkmark$ \\
\hline Economics, business \& finance & $\checkmark$ & $\checkmark$ & $\checkmark$ & $\checkmark$ & $\checkmark$ & $\checkmark$ \\
\hline Ecosystems, conservation & $\checkmark$ & $x$ & $\checkmark$ & $x$ & $\checkmark$ & $\checkmark$ \\
\hline Equity issues & $\checkmark$ & $\checkmark$ & $x$ & $\checkmark$ & $\sqrt{ }$ & $x$ \\
\hline Governance, legal \& policy & $x$ & $\checkmark$ & $\checkmark$ & $\checkmark$ & $\checkmark$ & $\checkmark$ \\
\hline Health-related & $\checkmark$ & $\checkmark$ & $\checkmark$ & $\checkmark$ & $\checkmark$ & $\checkmark$ \\
\hline Indigenous peoples & $\checkmark$ & $\checkmark$ & $\checkmark$ & $\checkmark$ & $x$ & $x$ \\
\hline Infrastructure & $x$ & $\checkmark$ & $\checkmark$ & $\checkmark$ & $x$ & $\checkmark$ \\
\hline Marine environment & $x$ & $\checkmark$ & $\checkmark$ & $x$ & $x$ & $x$ \\
\hline Monitoring \& evaluation & $x$ & $\checkmark$ & $\checkmark$ & $x$ & $\checkmark$ & $x$ \\
\hline Pathways & $x$ & $x$ & $x$ & $x$ & $\checkmark$ & $\checkmark$ \\
\hline Risk & $x$ & $x$ & $\checkmark$ & $x$ & $\checkmark$ & $\checkmark$ \\
\hline Scale-dependent $^{1}$ & $\checkmark$ & $\checkmark$ & $\checkmark$ & $x$ & $\checkmark$ & $\checkmark$ \\
\hline Tools for adaptation & $x$ & $\checkmark$ & $\checkmark$ & $\checkmark$ & $x$ & $\checkmark$ \\
\hline Water management & $\checkmark$ & $\checkmark$ & $\checkmark$ & $\checkmark$ & $\checkmark$ & $\checkmark$ \\
\hline
\end{tabular}

${ }^{1}$ Includes national, regional and local case studies, local knowledge etc.

Table 2 provides a first indication of how the emphasis within the conferences shifted over time. Some topics, particularly in the 'sector' category, always merited a complete parallel session. Others were important for a few years, but then disappeared, for example 'Marine environment'. 'Indigenous communities and adaptation' was present for four conferences, but did not appear at the last two conferences. Some topics have emerged more recently, for example 'Pathways to adaptation' and 'Risk management' were both present at the last two conferences while, with the exception of 'Risk management' at the 2013 conference, being absent at the previous four.

\section{Analysis of the abstracts}

The analysis began with 2476 submitted abstracts. However, we are only interested here in adaptation in Australia. Therefore, abstracts with a first author based overseas that did not include the words "Australia" or "Australian" were removed from the analysis. This reduced the number of abstracts for analysis to 1904 (Table 1).

We ask five questions in this paper about the evolution of adaptation theory and practice in Australia, that can usefully be explored by analysis of the conference abstracts:

1. What is the work experience of the first author submitting the abstract? Is he/she based in a research establishment, government or the private sector?

2. What sector is described as being adapted in the abstract?

3. What is the type of intervention described by the abstract? 
4. What is the stage of the adaptation being described?

5. What type of organisation is driving the adaptation described by the abstract?

For questions 2-5, the 1904 abstracts were read by a team of three researchers into adaptation (the first three authors of this paper). A classification for each question was set up. Next, samples of 50 abstracts were extracted randomly and read by all three researchers who then came together to compare and discuss their classifications for each abstract. Modifications to the classification system were made as appropriate. This process was repeated three times after which it was judged that the decisions made by the three researchers had converged sufficiently. The final classifications for the five questions are shown in Table 3. The abstracts were randomised with respect to conference year to remove any decision bias that may have emerged over time. Because of the varying numbers of abstracts submitted to each conference, most of the discussion which follows is based on the percentage of all abstracts at one of the six conferences falling into a particular category. 
Table 3: Categories used for the five questions

\section{Question 1:}

\section{Business:}

Consultants

Manufacturing, construction, service

Primary Industries

Utilities, transport \& infrastructure

\section{Government:}

Federal government $\&$ its agencies

State government $\&$ its agencies

Local government

Environmental management groups

Other:

International organisations operating in Australia

e.g. World Wide Fund for Nature (WWF)

Media

NGOs \& charities

Research:

Including research agencies such as

CSIRO, universities etc.

\section{Question 2:}

Biodiversity, ecosystems

Built environment, urban \& regional planning

Business, industry, manufacturing, construction

Coasts, coastal management \& communities

Community \& community sector

Cultural \& heritage sites

Disaster management (response \& recovery)

Education

Finance, banking, insurance

General, cross-sectoral

Health, hospitals, ambulance, public health

Legal

Not adaptation

Policy, governance \& government

Primary industries

Social welfare \& services, aged care

Utilities, transport \& infrastructure

\section{Question 3:}

Indigenous knowledge \& adaptation

Communication

Engagement \& consultation

Education \& training

General

On-ground intervention \& action

Research

Development \& application of software, tools, data

\section{Question 4:}

Risk management:

Pre-Planning

Planning

Implementation

Monitoring \& evaluation

Other:

Capacity building

Cross-stage

General

Question 5:

Not applicable

Government (in Australia):

Federal government \& its agencies

State government \& its agencies

Local government

Environmental management groups

\section{Business}

Consultants

Manufacturing, construction, service

Primary Industries

Utilities, transport \& infrastructure

Societal

Community

NGOs \& charity groups

Social welfare

Other

General

Indigenous bodies

Overseas government

Unclassifiable 
We hypothesise that systematic, observable changes will take place in the origin, focus and content of abstracts over the six conferences, which will reflect the course of adaptation in Australia.

\subsection{Question 1: What is the work experience of the first author submitting the abstract?}

If adaptation is maturing in Australia, we might expect a shift of emphasis from research to practice, and hence a higher proportion of abstract submissions from people responsible for responding to climate change, working in government, infrastructure provision, business and industry.

For each abstract, we extracted the organisation of the first author. Organisations were classified into four categories: Research, Government, Business and Other (representing only $4 \%$ of abstracts and not considered further). Figure 1 shows the change over time in the percentage of abstracts at each conference falling into the first three categories. Throughout, Research is dominant, peaking at a high of $78 \%$ of abstracts in 2013 then falling progressively to less than half $(47 \%)$ in 2018 . Abstracts from Business were stable at around $11 \%$ for the first three conferences, but having dropped to only $6 \%$ in 2014 they grew strongly to $30 \%$ of the total in 2018. Government representatives have grown strongly from a low of $9 \%$ in 2013 to a maximum of $19 \%$ in 2018.

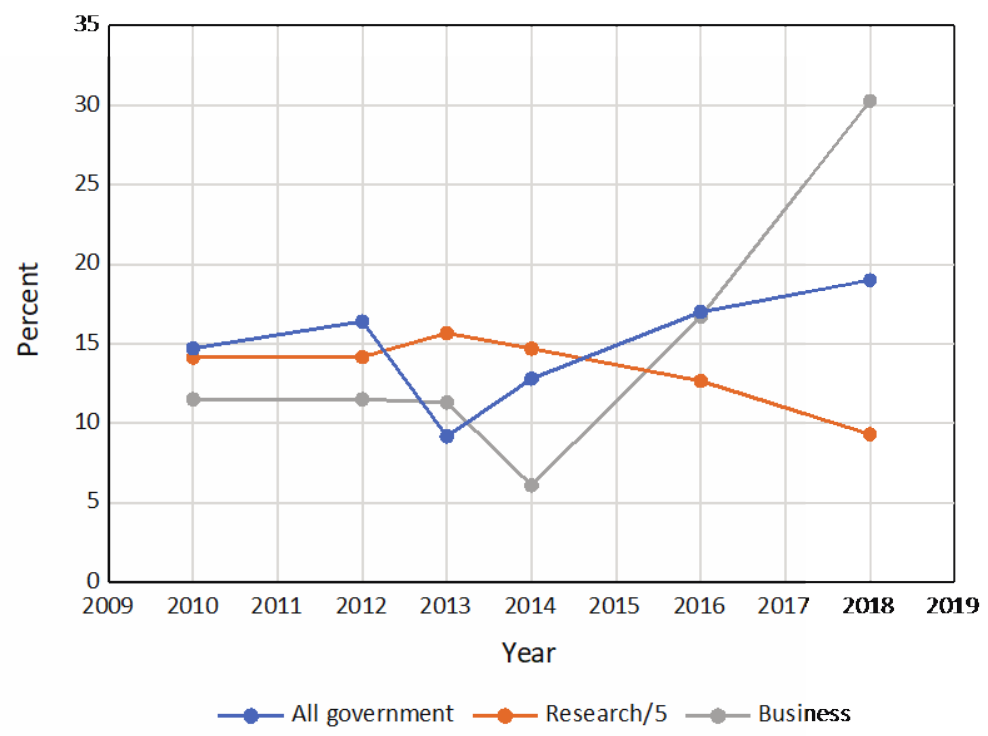

Figure 1 Abstracts classified by the work experience of the abstract submitter (Question 1), expressed as percentage of all abstracts submitted to each conference. Research abstracts divided by 5 .

The four categories were divided into 12 sub-categories (Table 3). Inspection of these shows that the Business category is made up almost entirely of consultants, who showed a sharp increase in abstract submission between 2014 and 2018. The trend towards relatively more abstracts from Government at recent conferences is driven predominantly by state and local government.

There is a possibility that the change of conference co-organiser from CSIRO (a primarily researchbased organisation) to Engineers Australia (mainly practitioner-based) between 2016 and 2018 affected trends in abstract submitters, i.e., the decline in researchers submitting abstracts and the 
growth from business (primarily consultants). It is important to note that CSIRO was invited in 2018 but declined. Rather than the trends in submitters being driven by the shift in co-organiser, it appears more likely that both are driven by the same causes: a decline in interest and financial investment in adaptation research. The trends in abstract submitters started before the change in co-organising institution: the relative decline in submissions from researchers started from a high in 2013, and the relative increase in submissions from business began from a low in 2014.

\subsection{Question 2: What sector is described as being adapted in the abstract?}

Abstracts were categorised according to the sector focused on, using the classification shown in Table 3. Ten categories contained, on average, more than $5 \%$ of abstracts across all conferences and, of these, four contained an average of more than $10 \%$. Together, these ten categories represent $89 \%$ of abstracts submitted.

The four most popular categories represented almost half of all abstracts on average (47\%) and were:

- Biodiversity and ecosystems (including natural resource management and water resources for ecosystems) $11 \%$

- Policy, government and governance $12 \%$

- Primary industries (includes agriculture, ranching and mining) $12 \%$

- General/cross-sectoral 12\% (for example, a non-sector-specific abstract dealing with adaptation barriers, or techniques such as risk assessment or adaptation pathways)

As Figure 2 shows, the proportion of Biodiversity and ecosystems abstracts shows a steady downward trend since 2012, when they reached $14 \%$, to 6\% in 2018. Policy, government and governance has no clear trend but reaches a maximum of $15 \%$ in 2018. The category of Primary industries also shows no clear trend but is at a minimum of 8\% in 2016 and 2018. 


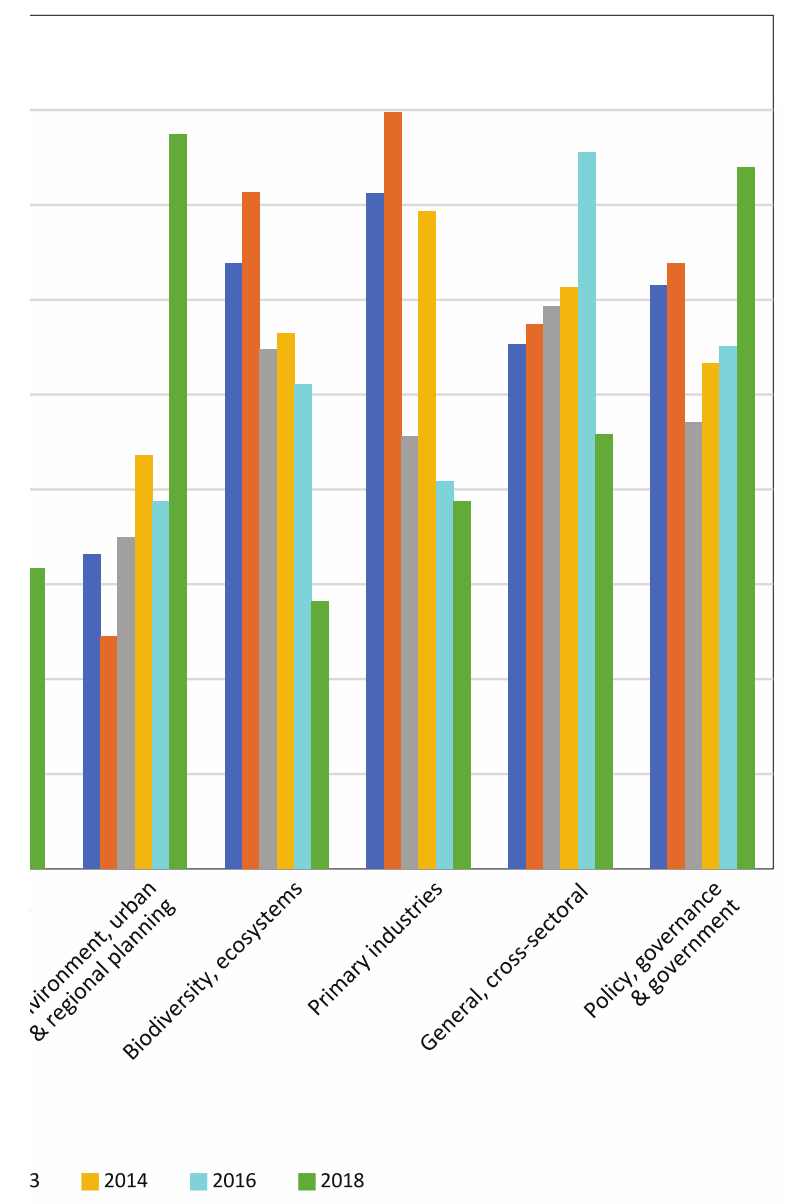

Figure 2 Abstracts classified by the sector described as being adapted (Question 2) expressed as percentage of all abstracts submitted to each conference. Sectors containing fewer than $5 \%$ abstracts not shown. 
A further six categories contained, on average, at least $5 \%$ of abstracts:

- Built environment, urban and regional planning (BE) $8 \%$

- Coasts, coastal management, coastal communities (Coasts) $7 \%$

- Community and community sector (CCS) $8 \%$

- Disaster management (response and recovery) $5 \%$

- Utilities, transport and infrastructure (UTI) $6 \%$

- Not adaptation (includes mitigation, sustainability, and climate science unrelated to adaptation e.g., the physics of climate models) $8 \%$

Of these, BE has trended upwards over time to a maximum of $16 \%$ in 2018 , the largest category in that year. UTI has generally trended upwards since 2012, with a jump to $10 \%$ of all abstracts in 2018 . Coasts sat an $6-7 \%$ for the first four conferences but then reached a maximum of $10 \%$ in 2016 , falling back to $8 \%$ in 2018. Both CCS and Not Adaptation peaked at the early conferences (at $12 \%$ in 2013 and $11 \%$ in 2010 respectively), subsequently declining to $6 \%$ and $4 \%$ respectively in 2018 . Disaster management shows no clear trend over time.

Again, it is possible that the shift in co-organiser from CSIRO to Engineers Australia affected trends in sector adapted. To explore this, we looked at trends in absolute numbers of abstracts submitted, rather than percentages. The two sectors most closely related to engineering are BE and UTI. Abstracts numbers from these two sectors are remarkably stable over time, in the twenties for BE and in the teens for UTI. The percentage trends shown in Figure 2 derive from steep declines in the absolute numbers of abstract submissions from the large categories ( $>200$ submissions in total):

- Primary industries - steady decline from 2014

- Biodiversity and ecosystems - steady decline from 2012

- General - steady decline from 2012

- Policy, government and governance - steady decline from 2014.

It is impossible to be certain, but the fact that there are no step jumps suggests that the change in co-organiser has had little if any effect.

Note that abstracts falling into the Not adaptation category were excluded from analysis in Questions 3-5.

\subsection{Question 3: What is the type of intervention described by the abstract?}

Eight categories (listed in Table 3) were identified to encompass the type of intervention. Keeping to a relatively small number of broad categories meant that ambiguities in classification were generally avoided. The largest category is Research $(45 \%)$ reflecting the dominance of the research community at the conferences. The next largest category is On-ground intervention/adaptation action, at $16 \%$. The General category, and the Development and application of software, tools and datasets, both represent $13 \%$ of abstracts. The former includes abstracts that do not focus on an adaptation intervention, as well as the many abstracts that lack a clear focus, for example reflecting broadly on the presence or absence of adaptation in the authors' community or region. The latter, very broad category encompasses everything from climate scenario development and impacts analysis for adaptation through to development of decision support tools and evaluation of their performance. It includes abstracts with a strong emphasis on data analysis (which will often be impacts analyses as a precursor to adaptation).

The abstracts which represent interactions with stakeholders and the community more broadly were surprisingly few in number. The three categories of Communication, Education and training and the Engagement and consultation process together only contributed $12 \%$ of abstracts. Note that the category of Engagement and consultation was reserved for abstracts focused on design and process, often outlining plans for a future program of consultation. Where an abstract described engagement 
and consultation as part of a wider program of adaptation, this was classified as On-Ground implementation. Finally, Indigenous knowledge and adaptation was a highly distinct category and contributed $1 \%$ of abstracts.

Most categories did not show a clear trend over time (Figure 3a). However, On-ground intervention/adaptation action did, starting from a low base of around $10 \%$ of abstracts in 2010 to $30 \%$ in 2018. This category includes interventions/actions of any category of adaptation - these might range from workshops to build community buy-in for an adaptation project through to largescale engineering projects to enhance infrastructure robustness. 
a)

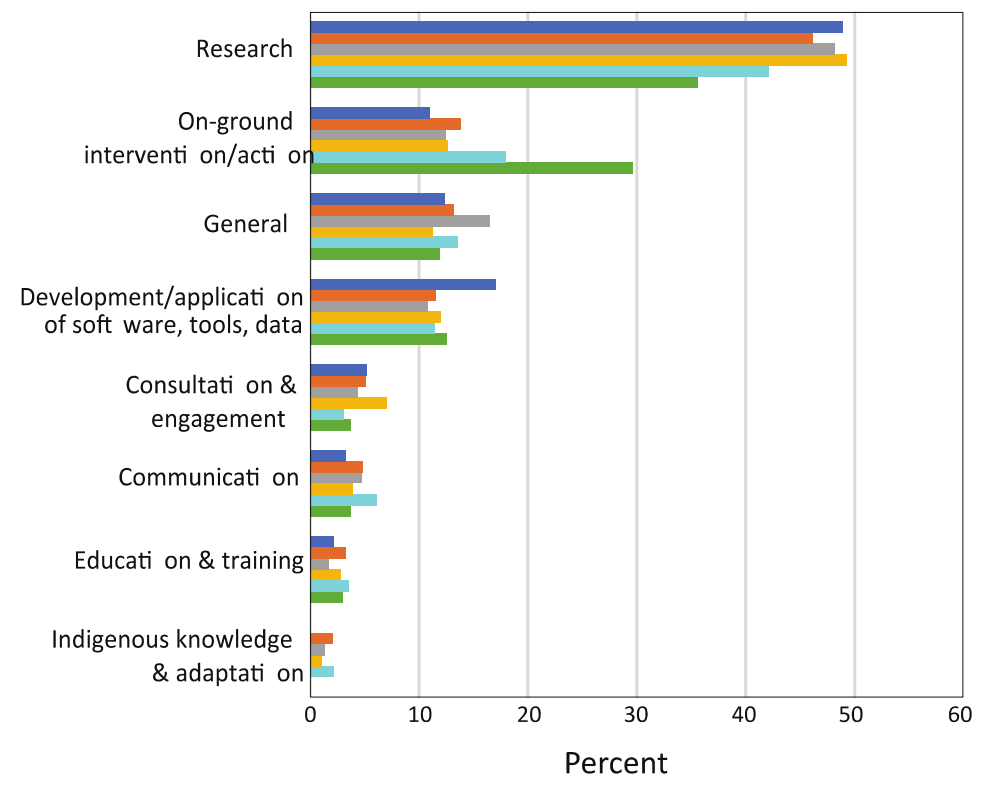

b)

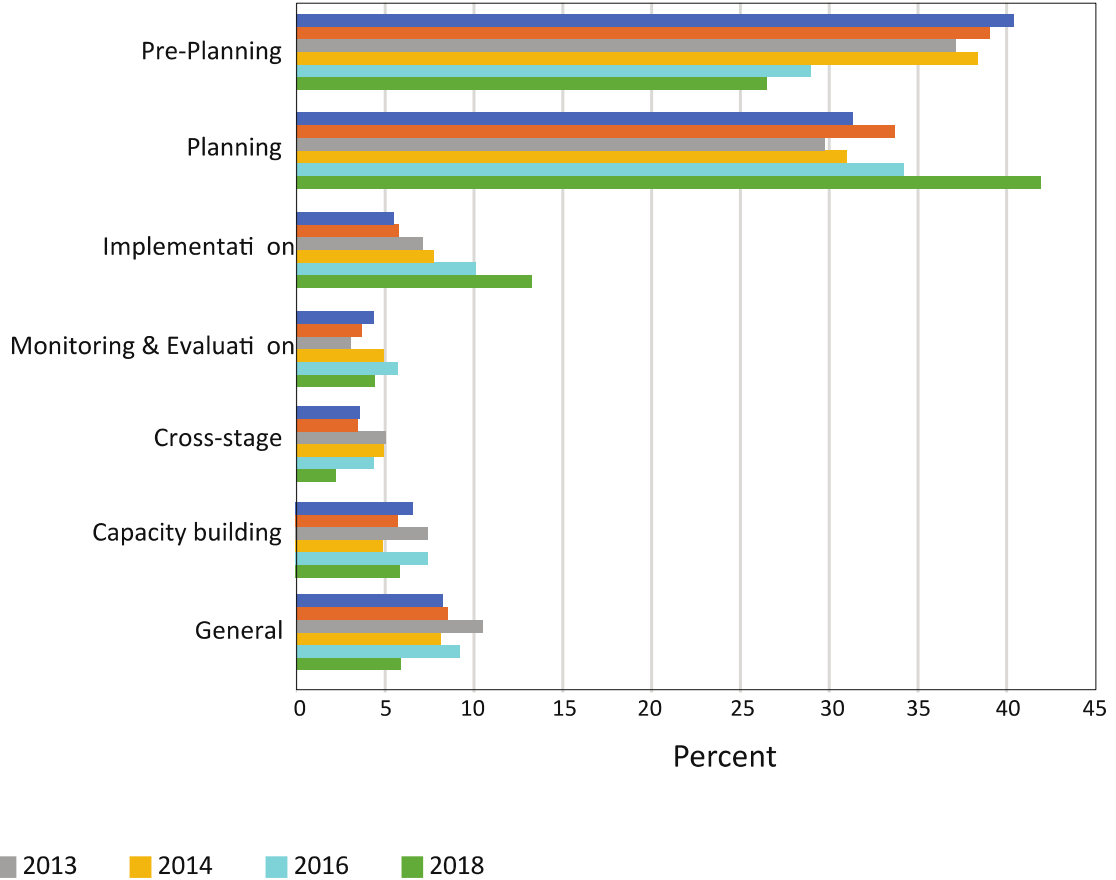

Figure 3 Abstracts classified by (a) type of intervention (Question 3) and (b) stage of adaptation (Question 4) expressed as percentage of all abstracts submitted to each conference 
We identified four broad categories of adaptation stage, drawn from the risk management frameworks developed for adaptation by a number of centres (e.g., Willows and Connell 2003; Tonmoy et al. 2019). These are: pre-planning, planning, implementation (action) and monitoring and evaluation (M\&E). Although Willows and Connell (2003) have eight stages in their risk management framework, and Tonmoy et al. (2019) have six (and these numbers are typical), trial and error demonstrated that more than four categories in the abstract evaluation meant that the consensus of classification between the three evaluators began to break down. Pre-planning was considered to include identification and analysis of impacts, where this is being carried out as a basis for adaptation, as well as activities such as software development (e.g., development of decision support resources) and climate services. Planning is a broad category ranging from assessing risks and vulnerability through to identification and evaluation of adaptation options and making a plan.

In addition to these categories related to risk management, we found it necessary to include the categories of Capacity building, Cross-stage and General. Cross-stage is a small category (4\% average), used only when an abstract spanned 3-4 stages of risk management. Abstracts covering two stages generally had an emphasis on one, and could be categorised accordingly. General (8\%) covered those abstracts which did not fall into any category, which often reported research projects (for example, PhD projects starting up).

The largest category is Pre-planning (35\%), followed by Planning (33\%). Implementation is relatively minor (only $8 \%$ ) but the smallest category is Monitoring and evaluation (4\%). This is as might be expected in a situation where adaptation is underway, but still in its infancy, with a large amount of pre-planning and planning, but little implementation and even less M\&E. Capacity building is happening and being reported but accounts for only $6 \%$ of abstracts - it would be good to think this is because capacity has been built or has become operationalised.

The trends over time are notable (Figure $3 b)$. First, considering the absolute number of abstracts submitted, and the three largest categories that represent stages in the adaptation journey (Preplanning, Planning and Implementation) we see that the relative number of abstracts in these three categories changed systematically over time. In 2010, Pre-planning was the largest category, with 147 abstracts, while Planning had 114 abstracts. In 2016, this reversed, with 66 abstracts for Preplanning and 78 for Planning. The gap widened in 2018, with 36 abstracts for Pre-planning and 57 for Planning. Implementation abstracts represented just 14\% of Pre-planning abstracts in 2010 (20 and 147 abstracts respectively), while by 2018 they represented half (18 and 36 respectively).

In terms of the percentage of abstracts submitted at each conference, the Pre-planning abstracts decline gradually between 2010 and 2018, representing $40 \%$ of all abstracts in 2010, but only $28 \%$ by 2018. Implementation abstracts increase gradually, from $6 \%$ in 2010 to $13 \%$ in 2018 . Although Planning abstracts do not have a strong trend, they accounted for $30-35 \%$ of all abstracts in the early conferences, rising to $42 \%$ in 2018.

\subsection{Question 5: What type of organisation is driving the adaptation described by the abstract?}

The inclusion of this question is an attempt to move past understanding the organisation of the person submitting the abstract (Question 1), or the sector being adapted (Question 2), to consider the organisation which is actually leading the action. For example, if a state government was undertaking a program to rehabilitate wetlands, and the abstract was submitted by a university 
research group hired to monitor the project, then the project would be described as Research under Question 1, Biodiversity and ecosystems under Question 2, and State government under Question 5.

We classified the abstracts into five main categories: Government (25\%), Business (15\%), Societal (7\%), Not applicable (42\%) and Other (11\%). These in turn were divided into 15 sub-categories (Table 3).

Of the five questions, this was the most problematic in terms of classification. Many abstracts did not describe a specific adaptation activity and hence, as noted, the Not applicable category is very large. Other abstracts placed the emphasis on impacts, spoke generally about what might be done to address those impacts, but did not speculate (except in the broadest terms) about what organisation might be responsible for taking action. In such a case, where possible, the three assessors made the decision to classify the abstract according to the organisation doing the adapting, even where that adaptation was only responsive. Where that was not possible, the abstract was classified as General (a sub-category of Other).

The Not applicable group showed an uneven but persistent decline over time (Figure 4). In 2010 it represented $45 \%$ of abstracts. This figure rose to a maximum of $50 \%$ in 2013 , but by 2018 only $34 \%$ of abstracts failed to describe some kind of adaptation activity. 


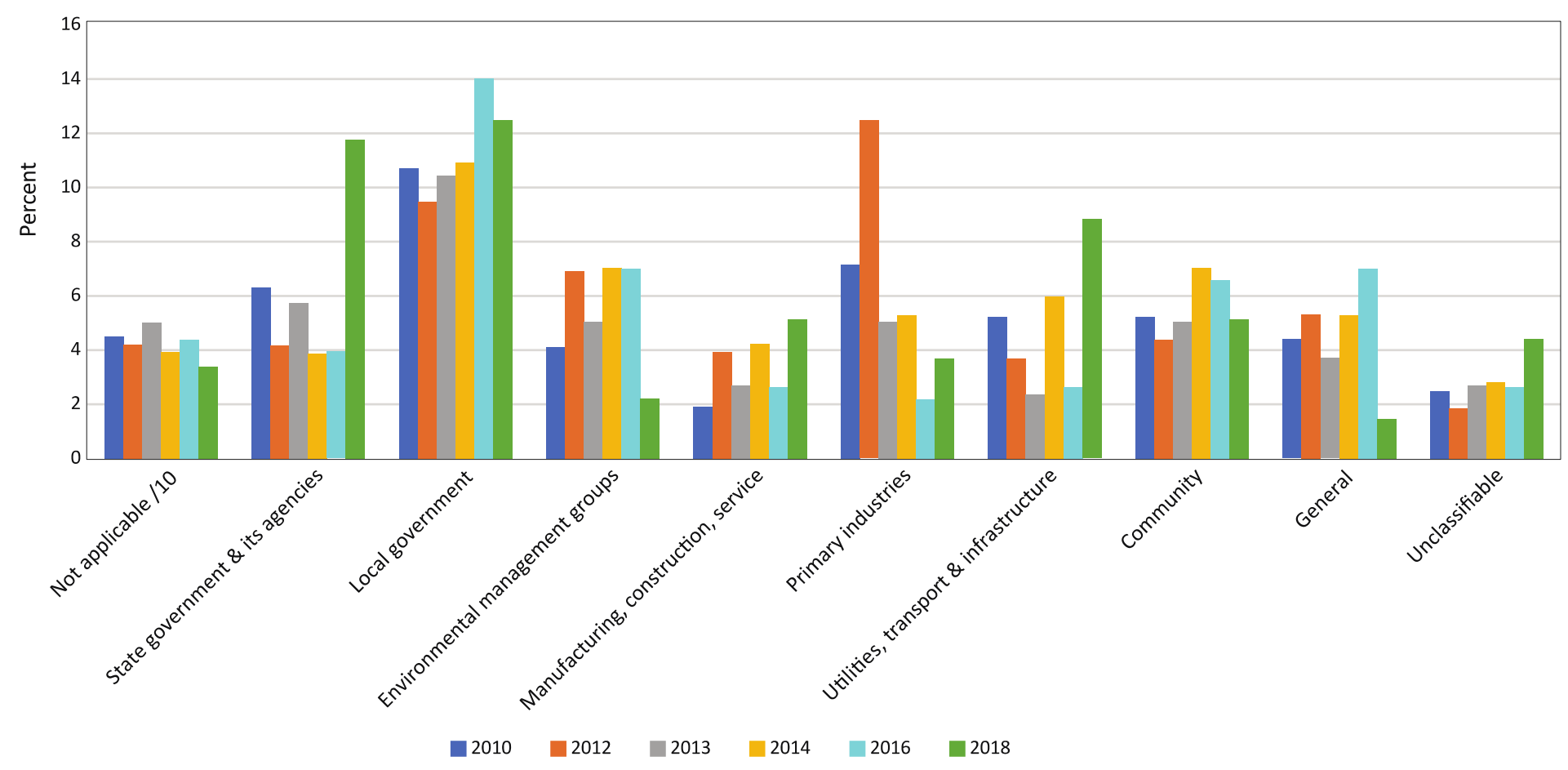

Figure 4 Abstracts classified by the type of organisation driving the adaptation described (Question 5), expressed as percentage of all abstracts submitted to each conference. The Not applicable category represents $42 \%$ of all abstracts and is divided by 10 . Categories containing fewer than $2 \%$ abstracts not shown. 
The Government category shows a gradual increase over time, from around $22-23 \%$ of abstracts in the early conferences to a high of $29 \%$ in 2018 . Within Government, the largest category is Local government (11\%). State government actions represented 6\%, and activities by Environmental management groups (which in Australia are mainly government agencies) represented $5 \%$. The increase over time comes primarily from local government, together with a surge in abstracts from state government at the final conference in 2018. Environmental management abstracts showed a substantial decline to $2 \%$ in 2018 (from $7 \%$ at the two previous conferences).

Business-related activities were dominated by Primary industries (6\%) and Utilities, transport and infrastructure (5\%). The category peaked in 2012 at $21 \%$ but then declined before returning to $19 \%$ in 2018. It is notable that abstracts describing actions in Primary industries declined over time, from a high of $13 \%$ in 2012 to only $4 \%$ in 2018.

The Societal sector, made up mainly of Community-related activities (6\%), but also including Social welfare (less than $1 \%$ ) and NGOs and charity groups (1.5\%), shows a strong increase in abstracts from a low of $5 \%$ in 2012 to over $8 \%$ at the two most recent conferences.

These abstracts, together with the Not applicable category, represent $89 \%$ of the whole. Of the remaining $11 \%$, only two categories have more than $2 \%$ of abstracts. These are the General category (5\%) and Unclassifiable (3\%). Neither exhibit a trend.

\section{Discussion}

The NCCARF conferences took place against a background of shifting national commitment to climate change research and action. At its inception in 2008, NCCARF was contractually required to allocate 30 million AUD to funding research projects. It set up a formal process involving identification of knowledge needs, external calls for proposals and proposal peer review. Between 2009 and 2013, around 100 research projects were funded, involving 37 of Australia's 43 universities (NCCARF 2014). At around the same time, the CSIRO set up the Climate Adaptation Flagship in 2007, and this carried out much important adaptation research until ceasing operation in 2014 (CSIRO 2015). Since then, there has been much less funding available for adaptation research (Granberg and Glover 2014). State governments have initiated research activities, but their programs are smaller, generally consisting of more prescriptive invitations to tender or directly commissioned work. These fluctuations have fed through to the number of publications on adaptation originating in Australia (Pearce et al. 2018) and must affect the volume and type of abstract being submitted to the NCCARF conference series.

As Table 1 shows, the number of abstracts submitted has been in steady decline since 2012 . This is despite the fact that attendance numbers, following a decline between 2010 and 2014, have stayed relatively constant at the three most recent conferences. Over that time, the figure for abstracts submitted as a percentage of attendees has declined from 69\% in 2014 to $50 \%$ in 2016 and $35 \%$ in 2018. This may be a reflection, in the absence of research funding, of a decline in the proportion of researchers attending the conferences compared to attendees from government and the private sector. Researchers made up 58\% of attendees in 2010 and 2012, but this has gradually declined to just $31 \%$ in 2018. The conferences may have come to be more of an opportunity for networking and 'catching up', rather than for the more traditional presentation of results from research.

Matching this shift in the proportions of attendees from different employment backgrounds is a shift in the organisational background of abstract first authors (Question 1). Abstract submitters with a research background peaked in 2013 but then declined progressively, while the proportion of 
abstract submitters from government (mainly state and local) and business (mainly consultants) peaked in 2018 at $19 \%$ for the former and $30 \%$ for the latter.

In terms of the other trends emerging from the analysis, Question 2 explored the sector being adapted. Biodiversity and ecosystems was one of the largest categories at $11 \%$, but showed a systematic downward trend across the six conferences to just $6 \%$ in 2018. Conversely, the Built environment ( $8 \%$ all abstracts) trended upwards over time to reach $16 \%$ in 2018.

Question 3 looked at the type of intervention described. The category was dominated by research (45\%). There was a lack of trends over time apart from On-ground interventions/adaptation actions, which moved from a low base of $10 \%$ in 2010 to represent $30 \%$ abstracts by 2018 . Researchfocussed abstracts have been in decline since 2012.

Question 4 examined adaptation stage, seeking to establish whether the abstracts indicate that adaptation has matured over time from pre-planning towards a greater emphasis on planning and implementation. Looking at both absolute numbers and percentages, this appears to be the case. Pre-planning abstracts declined from $40 \%$ of abstracts in 2010 to just $28 \%$ in 2018 whereas Implementation abstracts (although a small category) increased from $6 \%$ to $13 \%$ over the same period.

Finally, we explored the type of organisation driving the adaptation in Question 5. Close to half the abstracts did not describe a specific adaptation activity. For the remainder, few categories showed trends, but there was a clear decline over time in the proportion of abstracts describing adaptation in the primary industries, and a growth in those relating to government.

This analysis of NCCARF's conference series which took place throughout the 2010s shows clear trends towards:

- A reduction in the proportion of researchers attending conferences

- A decline in the proportion of attendees submitting abstracts

- An increase in the proportion of abstracts submitted by state and local government attendees and by consultants

- A shift in the focus of abstracts, from biodiversity and ecosystems and towards the built environment

- An increased proportion of abstracts describing on-ground intervention/adaptation action

- A higher proportion of abstracts describing implementation of adaptation action, and a lower proportion describing pre-planning activities

- Where an organisation is identified as driving or carrying out adaptation, a shift from a primary industry focus and a relative growth in the proportion of abstracts focussing on government.

How do these trends relate to, or illuminate, the progress of adaptation in Australia? A widelyrecognised aspect of adaptation is that there is often a strong emphasis on planning, and many insightful and comprehensive plans exist. However, barriers emerge when transitioning from planning to implementation (Waters et al. 2014; Deshpande et al. 2019; Shi 2019), such that clear, observable action does not necessarily emerge to build on the planning stage (Mimura et al. 2014). Mogelgaard et al. (2018) termed this the 'implementation gap' and identified four requirements to bridge that gap: finance, policy frameworks, information and tools, and leadership.

An analysis of responses to a survey of adaptation practitioners in Australia by Palutikof et al. (2019) identified lack of leadership, knowledge and community support as the three main barriers to 
action. These correspond broadly to the three common prerequisites identified for transformational change to take place (knowledge, institutional alignment, stakeholder values) (Lavorel et al. 2019), and to the values - rules - knowledge framing of Gorddard et al. (2016), indicating how fundamental they are in blocking the shift from observed adaptation progress to the transformations required to address current rates of climate change. This abstract analysis makes clear that, despite whatever barriers exist, reportable adaptation action is taking place in Australia, and although it still represents a small proportion of adaptation activity (compared, for example, to planning), that proportion is growing over time.

Few papers have explored the progress of adaptation in Australia. Those that do, however, confirm our finding that adaptation is underway, albeit with an emphasis on the early stages. Pearce et al. (2018) in their study of 390 peer-reviewed papers found that $85 \%$ described groundwork, $12 \%$ a mix of groundwork and concrete actions, and only $3 \%$ concrete actions alone. Similarly, Bradley et al. (2018) looking at adaptation in 67 coastal councils found that only $58 \%$ had published adaptation plans, and many of these dealt only with understanding the problem.

There has been a shift in the sectoral focus of abstracts. Pearce et al. (2018) found that $30 \%$ of Australian papers analysed were on agriculture, $21 \%$ were on coastal adaptation, and $14 \%$ on adaptation in the health sector. We also found primary industries to be important $(12.5 \%$ abstracts, ranked $1^{\text {st }}$ of 16 sectors) but coastal adaptation less so $\left(7 \%\right.$, ranked $\left.8^{\text {th }}\right)$ and health-related topics less so again $\left(4.7 \%\right.$, ranked $\left.11^{\text {th }}\right)$. Pearce et al. did not explore sectoral trends over time. We found that primary industries declined in importance over time: in 2010 the sector had the most abstracts submitted, but by 2018 had dropped to fifth place. Coastal adaptation has shown a clear increase over time. The health sector shows no clear trends. Other sectors demonstrating clear trends are: Biodiversity and ecosystems (declined in importance over time) and Built environment, urban and regional planning and Utilities, transport and infrastructure (both increased in importance).

In parallel, we see a shift from researcher-submitted to practitioner-submitted abstracts. This may be linked in part to lack of money for research: Australia has seen a reduction in total government spend on research and development (R\&D) in the last decade (ABS 2018). Government funding for climate change adaptation research has also declined (O'Donnell and Mummery 2017).

The approach to adaptation tracking presented here, exploring conference abstracts, is complementary to literature-based analyses of government policy documents (e.g., Woodruff and Regan 2019) and peer-reviewed literature (e.g., Pearce et al. 2018). However, because conference abstracts are relatively easy and quick to prepare, our approach should capture a wider spectrum of adaptation activity, and reveal it more rapidly than tracking based on more formal documentation. Literature-based tracking cannot capture some forms of adaptation such as household-level actions in response to perceived climate trends (e.g., installation of rainwater tanks) and company adaptation which is confidential or mainstreamed into risk registers. Indicator-based approaches (e.g., Ford et al. 2013) may be able to capture these systematically, especially if reporting is made mandatory. Because of the relatively small number of abstracts involved, we were able to read and classify each by hand. This runs risks such as different assessors classifying the same abstract in different ways, and creep over time in how one assessor classifies abstracts. We describe in this paper how we sought to overcome these risks. Approaches using data analysis software to search for words and phrases are emerging (e.g., Lesnikowski et al. 2019) which ensure consistency, and which can process large numbers of documents. However, it is hard to see how these can deliver the richness of analysis that can be achieved by expert evaluation.

\section{Conclusions}


This analysis of abstracts submitted to the NCCARF conferences tells a story of consistent trends. There has been, over time, a move towards implementation of adaptation actions, with a lessening emphasis on planning. Abstracts are more likely to be submitted by decision-makers and practitioners in government and the consultancy business, and less likely to be submitted by researchers. The sectoral focus of these abstracts has shifted from the natural environment and primary industries, and towards the built environment and utilities.

It would be good to suppose that these trends are driven by a maturation of adaptation. This may be in part the case, but there is also the likelihood that lack of funding for adaptation R\&D is playing a role. We note that, over time, there has been a reduction in the absolute number of attendees at the conference, which speaks to a lack of funding. Researchers of necessity must follow the money, and if there is a lack of government funding for adaptation, they will take their skills and expertise to other scientific fields. Many researchers have pointed to lack of knowledge as a barrier to adaptation (Archie et al. 2014; Mogelgaard et al. 2018; Palutikof et al. 2019). The Australian government's think tank, the Productivity Commission, stated in its Barriers to Effective Climate Change Adaptation report that "A barrier to effective adaptation can arise where governments do not provide (or underprovide) environmental research, information and monitoring that benefit the community" (Productivity Commission 2012).

It is likely that a combination of the two factors, adaptation maturation and lack of funding for research, is driving the trends observed in the abstracts submitted to the NCCARF conference series. The trends that we observe in Australia have universal relevance, and it would be useful to see the approach here applied to other adaptation conferences such as the international Adaptation Futures conference series and the European Climate Change Adaptation conference series.

Research targeted on identified knowledge gaps is essential to support effective adaptation. In the absence of that research, adaptation is likely to focus increasingly on short-term incremental actions to address observed climate fluctuations, rather than the long-term strategic actions that are required to ensure sustainability under climate change. 


\section{References}

ABS (2018) Government resources devoted to research and experimental development. In: 8109.0 Research and Experimental Development, Government and Private Non-Profit Organisations, Australia, 2016-17. Australian Bureau of Statistics, Canberra.

http://www.abs.gov.au/AUSSTATS/abs@.nsf/allprimarymainfeatures/OAE638AFEA290E1BCA256964 007CF648?opendocument accessed 8 May 2019.

Archie KM, Dilling L, Milford JB, Pampel FC (2014) Unpacking the 'information barrier': comparing perspectives on information as a barrier to climate change adaptation in the interior mountain West. J Environ Manage 133:397-410. http://dx.doi.org/10.1016/j.jenvman.2013.12.015

Austin SE, Ford JD, Berrang-Ford L et al (2015) Public health adaptation to climate change in Canadian jurisdictions. Int J Environ Res Public Health 12:623-651.

http://dx.doi.org/10.3390/ijerph120100623

Barnett J, Evans LS, Gross C et al (2015) From barriers to limits to climate change adaptation: path dependency and the speed of change. Ecol Soc 20(3):5. http://dx.doi.org/10.5751/ES-07698-200305

Biagini B, Bierbaum R, Stults M et al (2014) A typology of adaptation actions: a global look at climate adaptation actions financed through the Global Environment Facility. Global Environ Chang 25: 97108. http://dx.doi.org/10.1016/j.gloenvcha.2014.01.003

Bowman M, Minas S (2019) Resilience through interlinkage: the green climate fund and climate finance governance. Climate Policy 19: 342-353. http://dx.doi.org/10.1080/14693062.2018.1513358

Bradley M, van Putten I, Sheaves M (2015) The pace and progress of adaptation: marine climate change preparedness in Australia's coastal communities. Marine Policy 53:13-20.

https://doi.org/10.1016/j.marpol.2014.11.004

Chen C, Noble I, HellmannJ et al (2015) University of Notre Dame Global Adaptation Index Country Index Technical Report. University of Notre Dame, Notre Dame.

https://gain.nd.edu/assets/254377/nd_gain_technical_document_2015.pdf accessed 8 May 2019

CSIRO (2015) Explore CSIRO's past and present climate adaptation research. Commonwealth Scientific and Industrial Research Organisation, Canberra. https://research.csiro.au/climate/ accessed 8 May 2019

Deshpande T, Michael K, Bhaskara K (2019) Barriers and enablers of local adaptive measures: a case study of Bengaluru's informal settlement dwellers. Local Environment 24:167-179. http://dx.doi.org/10.1080/13549839.2018.1555578

Donner SD, Kandlikar M, Webber S (2016) Measuring and tracking the flow of climate change adaptation aid to the developing world. Environ Res Lett 11:054006. http://dx.doi.org/10.1088/17489326/11/5/054006

Ford JD, King D (2015) A framework for examining adaptation readiness. Mitig Adapt Strateg Glob Change 20:505:526. http://dx.doi.org/10.1007/s11027-013-9505-8

Ford JD, Berrang-Ford L (2016) The 4Cs of adaptation tracking: consistency, comparability, comprehensiveness, coherency. Mitig Adapt Strateg Glob Change 21:839-859.

https://doi.org/10.1007/s11027-014-9627-7 
Ford JD, Berrang-Ford L, Paterson J (2011) A systematic review of observed climate change adaptation in developed nations. Climatic Change 106:327-336. https://doi.org/10.1007/s10584011-0045-5

Ford JD, Berrang-Ford L, Lesnikowski A et al (2013) How to track adaptation to climate change: a typology of approaches for national-level application. Ecol Soc 18:40. http://dx.doi.org/10.5751/ES05732-180340

GIZ (2014) Monitoring and evaluating adaptation at aggregated levels: a comparative analysis of ten systems. Deutsche Gesellschaft für Internationale Zusammenarbeit, Bonn

Gorddard R, Colloff MJ, Wise RM, Ware D, Dunlop M (2016) Values, rules and knowledge: adaptation as change in the decision context. Environ Sci Policy 57:60-69.

https://doi.org/10.1016/j.envsci.2015.12.004

Granberg M, Glover L (2014) Adaptation and maladaptation in Australian national climate change policy. J Environ Pol Plan 16:147-159. https://doi.org/10.1080/1523908X.2013.823857

Kamperman H, Biesbroek R (2017) Measuring progress on climate change adaptation policy by Dutch water boards. Water Resour Manage 31:4557-4570. https://doi.org/10.1007/s11269-017-1765-8

Kinley R (2017) Climate change after Paris: from turning point to transformation. Climate Policy 17:915. https://doi.org/10.1080/14693062.2016.1191009

Lavorel S, Colloff MJ, Locatelli B, Gorddard R, Prober SM (2019) Mustering the power of ecosystems for adaptation to climate change. Environ Sci Policy 92:87-97.

https://doi.org/10.1016/j.envsci.2018.11.010

Leemans R, Vellinga P (2017) The scientific motivation of the internationally agreed 'well below 2 degrees C' climate protection target: a historical perspective. Curr Opin Env Sust 26-27:134-142. https://doi.org/10.1016/j.cosust.2017.07.010

Lesnikowski A, Ford JD, Berrang-Ford L et al (2015) How are we adapting to climate change? A global assessment. Mitig Adapt Strateg Glob Change 20:277-293. https://doi.org/10.1007/s11027-013-9491$\mathrm{x}$

Lesnikowski A, Ford J, Biesbroek R (2016) National-level progress on adaptation. Nature Climate Change 6:261-265. https://doi.org/10.1038/NCLIMATE2863

Lesnikowski A, Belfer E, Rodman E et al (2019) Frontiers in data analytics for adaptation research: topic modelling. WIREs Clim Change 10:e576. https://doi.org/10.1002/wcc.576

Ling SD, Hobday AJ (2019) National research planning accelerates relevance and immediacy of climate-adaptation science. Mar Freshwater Res 70:62-70. https://doi.org/10.1071/MF17330

Mimura N, Pulwarty RS, Duc DM et al (2014) Adaptation planning and implementation. In: Field CB, Barros VR, Dokken DJ et al. (eds.) Climate Change 2014: Impacts, Adaptation, and Vulnerability. Part A: Global and Sectoral Aspects. Contribution of Working Group II to the Fifth Assessment Report of the Intergovernmental Panel on Climate Change, Cambridge University Press, Cambridge and New York, pp 869-898 
Mogelgaard K, Dinshaw A, Ginoya N et al (2018) From planning to action: mainstreaming climate change adaptation into development. Working Paper, World Resources Institute, Washington, DC. https://www.wri.org/publication/climate-planning-to-action. Accessed 8 May 2019.

Moloney S, McClaren H (2018) Designing a 'fit-for-purpose' approach to tracking progress on climate change adaptation and resilience: learning from local governments in Australia. In: Yamagata $Y$, Sharifi A (eds) Resilience-Oriented Urban Planning, Lecture Notes in Energy 65, Springer, Cham. https://doi.org/10.1007/978-3-319-75798-8_4

Morgan EA, Nalau J, Mackey B (2019) Assessing the alignment of national-level adaptation plans to the Paris Agreement. Environ Sci Policy 93:208-220. https://doi.org/10.1016/j.envsci.2018.10.012

NCCARF (2014) NCCARF 2008-2013: The first five years. National Climate Change Adaptation Research Facility, Gold Coast. https://www.nccarf.edu.au/publications/nccarf-2008-2013-first-fiveyears accessed 2 May 2019

O'Donnell T, Mummery J (2017) The 2017 budget has axed research to help Australia adapt to climate change. The Conversation 11 May 2017. https://theconversation.com/the-2017-budget-hasaxed-research-to-help-australia-adapt-to-climate-change-77477 accessed 8 May 2019.

Palutikof JP, Leitch AM, Rissik D et al (2019) Overcoming knowledge barriers to adaptation using a decision support framework. Climatic Change 153:607-624. https://doi.org/10.1007/s10584-0182177-3

Pearce TD, Rodriguez EH, Fawcett D and Ford JD (2018) How is Australia adapting to climate change based on a systematic review? Sustainability 10:3280. https://doi.org/10.3390/su10093280.

Productivity Commission (2012) Barriers to Effective Climate Change Adaptation. Report No. 59, Final Inquiry Report, Canberra.

Ray AD, Grannis J (2015) From planning to action: implementation of state climate change adaptation plans. Michigan Journal of Sustainability 3:5-28.

http://dx.doi.org/10.3998/mjs.12333712.0003.001

Shi L (2019) Promise and paradox of metropolitan regional climate adaptation. Environ Sci Policy 92:262-274. http://dx.doi.org/10.1016/j.envsci.2018.11.002

Street R, Di Mauro M, Humphrey K, et al (2017) UK Climate Change Risk Assessment Evidence Report: Chapter 8, Cross-cutting Issues. Report prepared for the Adaptation Sub-Committee of the Committee on Climate Change, London

Suk JE, Ebi KL, Vose D et al (2014) Indicators for tracking European vulnerabilities to the risks of infectious disease transmission due to climate change. Int J Environ Res Public Health 11:2218-2235. http://dx.doi.org/10.3390/ijerph110202218

Tonmoy FN, Rissik D, Palutikof JP (2019) A three-tier risk assessment process for climate change adaptation planning at a local scale. Climatic Change 153:539-557. https://doi.org/10.1007/s10584019-02367-z 
Waters E, Barnett J, Puleston A (2014) Contrasting perspectives on barriers to adaptation in Australian climate change policy. Climatic Change 124:691-702. https://doi.org/10.1007/s10584014-1138-8

Willows RI, Connell RK (eds) (2003) Climate adaptation: risk, uncertainty and decision-making. UKCIP Technical Report. UKCIP, Oxford.

Woodruff SC, Regan P (2019) Quality of national adaptation plans and opportunities for improvement. Mitig Adapt Strateg Glob Change 24:53-71. https://doi.org/10.1007/s11027-0189794-z 